\title{
Penectomia parcial em equino com carcinoma espinocelular: relato de caso
}

\section{Partial penectomy in equine with spinocellular carcinoma: case report}

\section{Resumo}

O carcinoma espinocelular, ou carcinoma epidermóide, é uma neoplasia maligna de células escamosas. Possui crescimento rápido nas células epidérmicas, sendo comumente encontrado na espécie equina, em regiões como pênis e prepúcio, tendo maior predileção por animais de idade avançada e não castrados. O diagnóstico diferencial é baseado em fatores como sintomatologia clínica e citologia, assim como no exame histopatológico da lesão. Dentre as possibilidades para acometimento em pênis, a remoção cirúrgica da lesão, ou seja, a penectomia, é o tratamento de eleição para o carcinoma espinocelular, pontuando que, nessa neoplasia, é comum haver casos de recidiva. Este trabalho relata um caso de carcinoma epidermóide em um equino sem raça definida (SRD) atendido no hospital veterinário (HV) da Faculdade Dr. Francisco Maeda e descreve a técnica cirúrgica utilizada para o tratamento.

\section{Abstract}

Squamous cell carcinoma is a malignant cell neoplasm. It grows rapidly in epidermal cells and is commonly found in the equine species, in regions such as penis and foreskin, with a higher predilection for old and non-castrated animals. The differential diagnosis is based on factors such as clinical symptomatology and cytology, as well as in the histopathological examination of the lesion. Among the possibilities for penile involvement, the surgical removal of the lesion, i.e., penectomy, is the treatment of choice for squamous cell carcinoma - although it is worth noting that, in this neoplasm, there are common cases of relapse. This article is a case report of squamous cell carcinoma in an SRD (unknown breed horse) attended at the Veterinary Hospital (H.V.) of the Dr. Francisco Maeda Faculty, describing the surgical technique used for the treatment. 
Letícia Nascimento Ramalho ${ }^{1}$

Isabela Beatriz Manzan'1

Guilherme Luiz Gomes da Silva ${ }^{1}$

Carolina Isabel Soriano Oporto ${ }^{1}$

Diego Iwao Yamada ${ }^{1}$

Luiz Roberto Pena de Andrade Junior ${ }^{1}$
Rua Taiá, 414, Jardim Marajoara

Ituverava/SP, Brasil, CEP: 14500-000

囚 letticianramalho@gmail.com

\section{Palavras-chave}

Neoplasia. Equino. Cirurgia. Pênis.

\section{Keywords}

Neoplasia. Equine. Surgery. Penis.

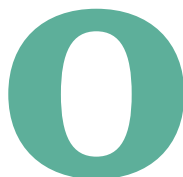

carcinoma espinocelular, também conhecido como carcinoma epidermóide, é um tipo de neoplasia de caráter invasivo que acomete células escamosas, apresentando crescimento rápido nas células epidérmicas e se diferenciando a partir de queratinócitos. Comumente encontrado na espécie equina, em regiões muco-cutâneas, como pênis e prepúcio, tem maior predileção por animais de idade avançada e não castrados (XAVIER; NOGUEIRA; FERNANDES, 2008).

Os animais acometidos podem apresentar aumento de volume na região do pênis e prepúcio, tendo dificuldade na exposição peniana, retenção urinária e comprometimento do canal uretral (XAVIER; NOGUEIRA; FERNANDES, 2008).

O diagnóstico diferencial é baseado em fatores como sintomatologia clínica, citologia e exame histopatológico, no qual são encontradas alterações como espessamento da derme e trabéculas de células epiteliais neoplásicas. Tais alterações só podem ser observadas no microscópio óptico, pois a aparência macroscópica do carcinoma epidermóide pode ser semelhante à habronemose cutânea (BATAIER et al., 2012). 


\section{Material e métodos}

Foi atendido no hospital veterinário (HV) um equino macho, sem raça definida (SRD), de aproximadamente vinte anos de idade. No exame clínico, o animal se apresentava prostrado, com baixo escore corporal (2), edema na região de prepúcio e pênis e lesões desde o corpo deste, seguindo em direção à glande (Figura 1), além de parâmetros fisiológicos alterados, como a frequência cardíaca - com 60 batimentos/minuto -, frequência respiratória de 36 movimentos respiratórios/minuto e mucosa anêmica.

À palpação do órgão genital, foi constatado comprometimento de processo uretral devido a fibrose na região da glande peniana. Inicialmente realizou-se sondagem uretral, uma vez que o fluxo da urina estava interrompido devido ao alto grau de acometimento do órgão em questão. De acordo com a avaliação clínica e laboratorial do paciente, o tratamento de eleição para enfermidade foi a penectomia parcial.

Para a realização do procedimento, o animal foi submetido a jejum alimentar durante 24 horas e, como medida de prevenção, houve tratamento com antibioticoterapia (gentamicina $6,6 \mathrm{mg} / \mathrm{kg} / \mathrm{q} 24 \mathrm{~h}$ i.v., penicilina benzatina e procaína $40.000 \mathrm{UI} / \mathrm{kg} / \mathrm{q} 24 \mathrm{~h} \mathrm{i} . \mathrm{m}$ ), iniciado 24 horas antes do procedimento cirúrgico e mantido durante oito dias após sua realização.

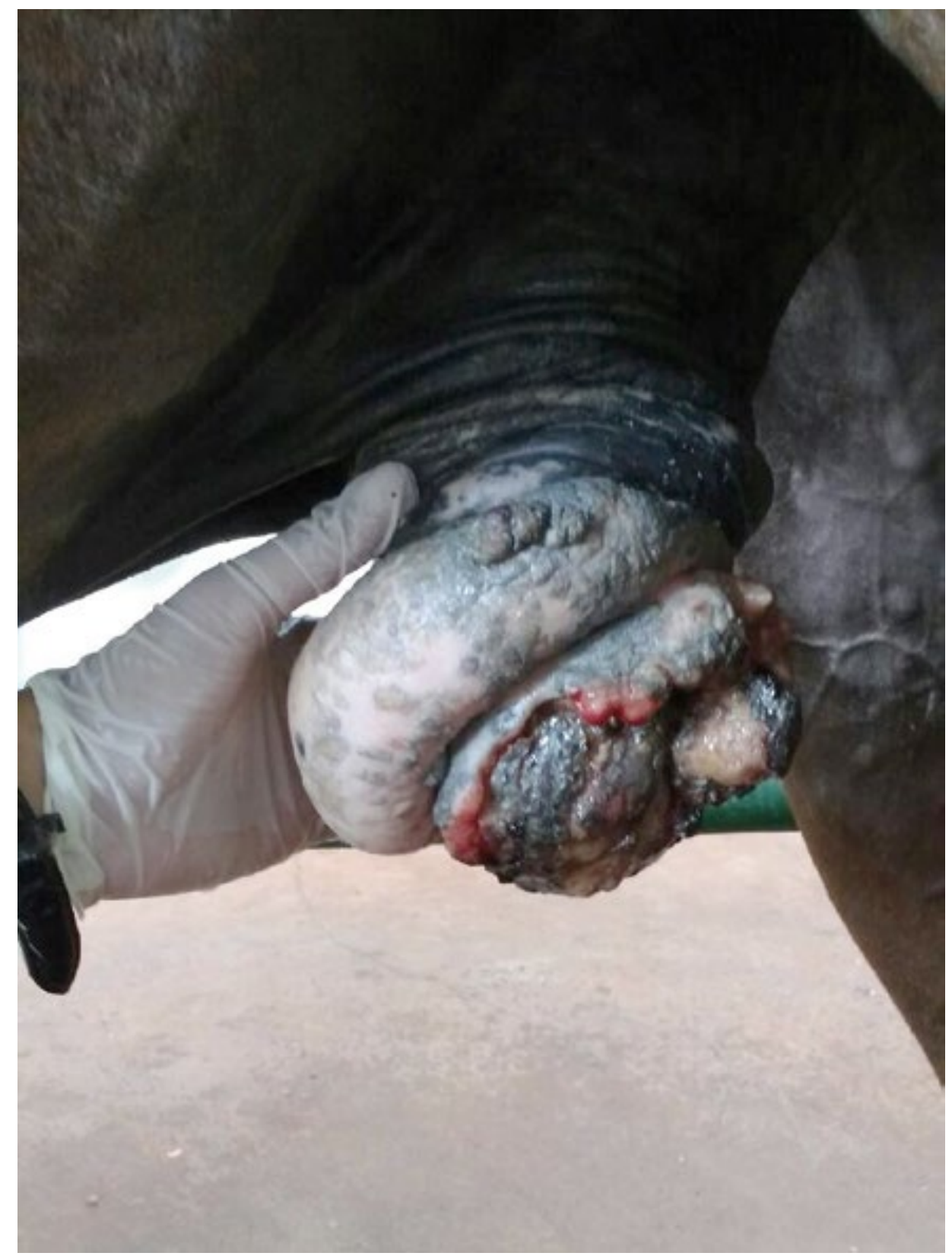

Figura 1 - Lesão ulcerativa em corpo e glande peniana de equino. Fonte: Arquivo pessoal. 
O animal foi mantido em posição quadrupedal e o protocolo anestésico de escolha foi a administração, pela via intravenosa, de bolus de detomidina $(0,01 \mathrm{mg} / \mathrm{kg})$ em duas aplicações. Para a anestesia local, foi realizado um torniquete na direção proximal (Figura 2) ao local de amputação, com aplicação de $10 \mathrm{ml}$ de lidocaína em uma veia peniana, complementada pela administração de $15 \mathrm{ml}$, divididos em três lados da incisão triangular na porção caudal do pênis.

Com o animal anestesiado, utilizando-se um cateter como guia uretral (Figura 3), foram realizadas incisões em cada lado do triângulo (Figura 4), dividindo a uretra longitudinalmente e desprezando o tecido conectivo do interior. As bordas da uretra foram suturadas na pele ao longo dos lados da incisão, utilizando pontos simples separados com fio Vicryl 2-0. Em seguida, foi realizada a transecção pela uretra peniana, estendendo-se da base do triângulo até um ângulo levemente oblíquo na direção cranial à superfície dorsal do pênis (Figura 5). A túnica albugínea foi fechada sobre os corpos cavernosos do pênis e, subsequente a isso, a remoção do torniquete foi realizada de forma gradativa. Ao término da cirurgia, foram aplicadas 10.000 UI i.m. de soro antitetânico.

O tratamento pós-operatório consistiu na continuidade da antibioticoterapia e da aplicação de meloxicam $2 \%$ i.v. $(0,6 \mathrm{mg} / \mathrm{kg} / \mathrm{q} 24 \mathrm{~h})$ durante sete dias, além de duchas frias $\mathrm{q} 12 \mathrm{~h}$ para a redução do edema local. Para a manutenção dos níveis plasmáticos ideais, ao término da antibioticoterapia preventiva foi instituído o tratamento com sulfametoxazol em associação a trimetropin (15 mg/kg/q48h i.m.), totalizando três aplicações. Após doze dias, foram removidos os pontos de sutura da uretra (Figura 6) e o animal foi liberado. Fragmentos do tecido comprometido foram retirados e enviados para análise histopatológica, na qual foi confirmado o carcinoma espinocelular.

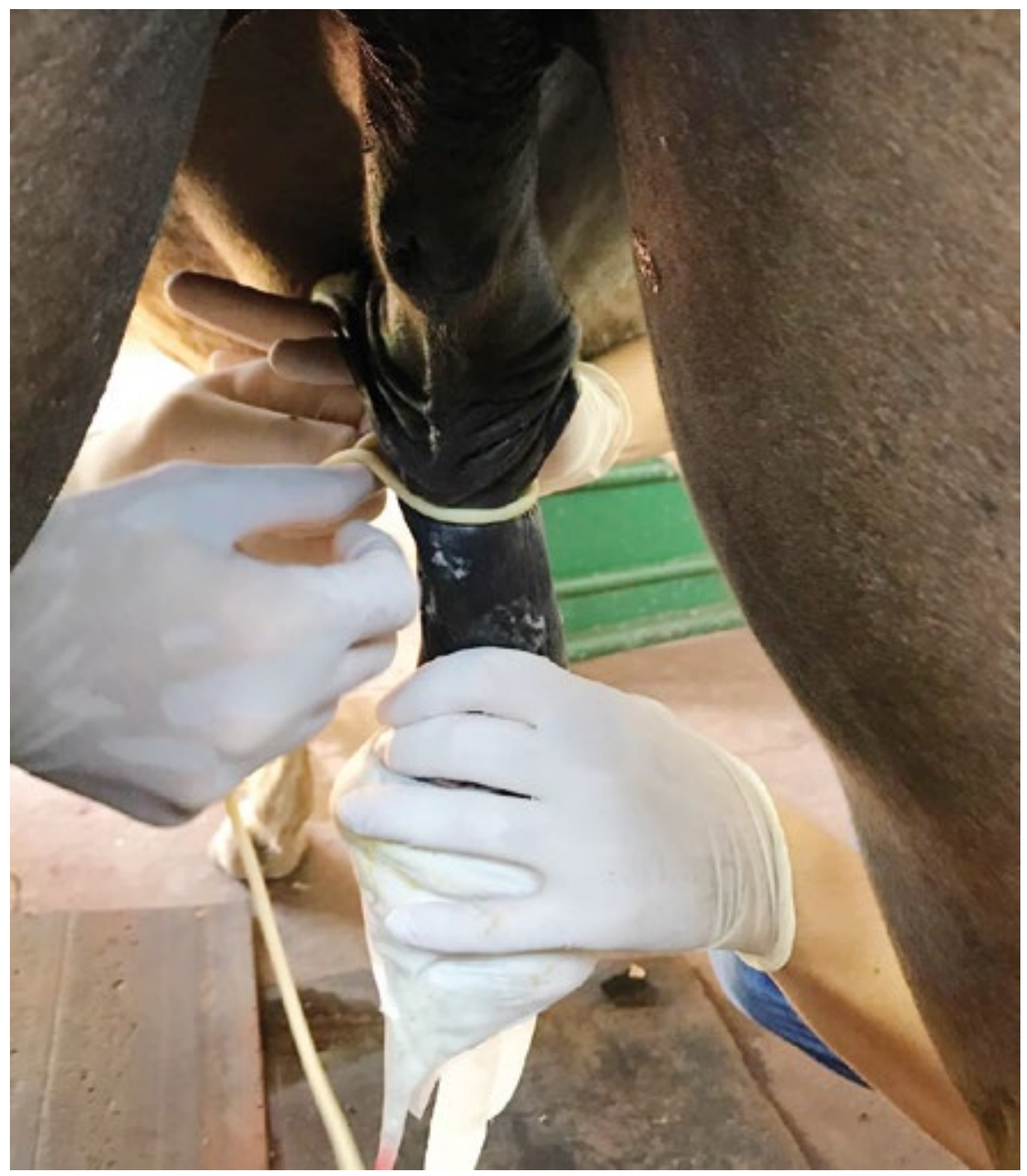

Figura 2 - Aplicação de torniquete proximal ao local de amputação.

Fonte: Arquivo pessoal. 


\section{Resultados e discussão}

O carcinoma espinocelular é denominado também de carcinoma de células escamosas ou carcinoma epidermóide. Trata-se de um tumor encontrado com mais frequência na região de pele - porém, existem poucos estudos referentes a seu tratamento e grau de diferenciação (MARTINS et al., 2007; VAN DEN TOP et al., 2008).

Este trabalho relata o diagnóstico e tratamento cirúrgico de um equino com carcinoma espinocelular na região do pênis e prepúcio. Corroborando Pereira et al. (2012), mostra que esse tipo de neoplasia é comumente encontrado em animais castrados em junções muco-cutâneas.
Alguns autores relatam que o carcinoma espinocelular é comum em machos castrados e sugerem o esmegma como principal agente etiológico (MARTINS et al., 2007), condizendo com o caso atendido. Em cavalos castrados, o acúmulo de esmegma é maior do que nos garanhões. Porém, ainda não foi esclarecido se o desenvolvimento do tumor está relacionado a uma irritação crônica ou a substâncias carcinogênicas do esmegma (CARLOS et al., 2016). Scott e Miller (2004) referem que os animais que manifestam carcinoma de células escamosas (CCE) possuem idade entre 10 e 12 anos, de modo que Van den Top et al. (2008) afirmam que a idade é de 17 a 20 anos.

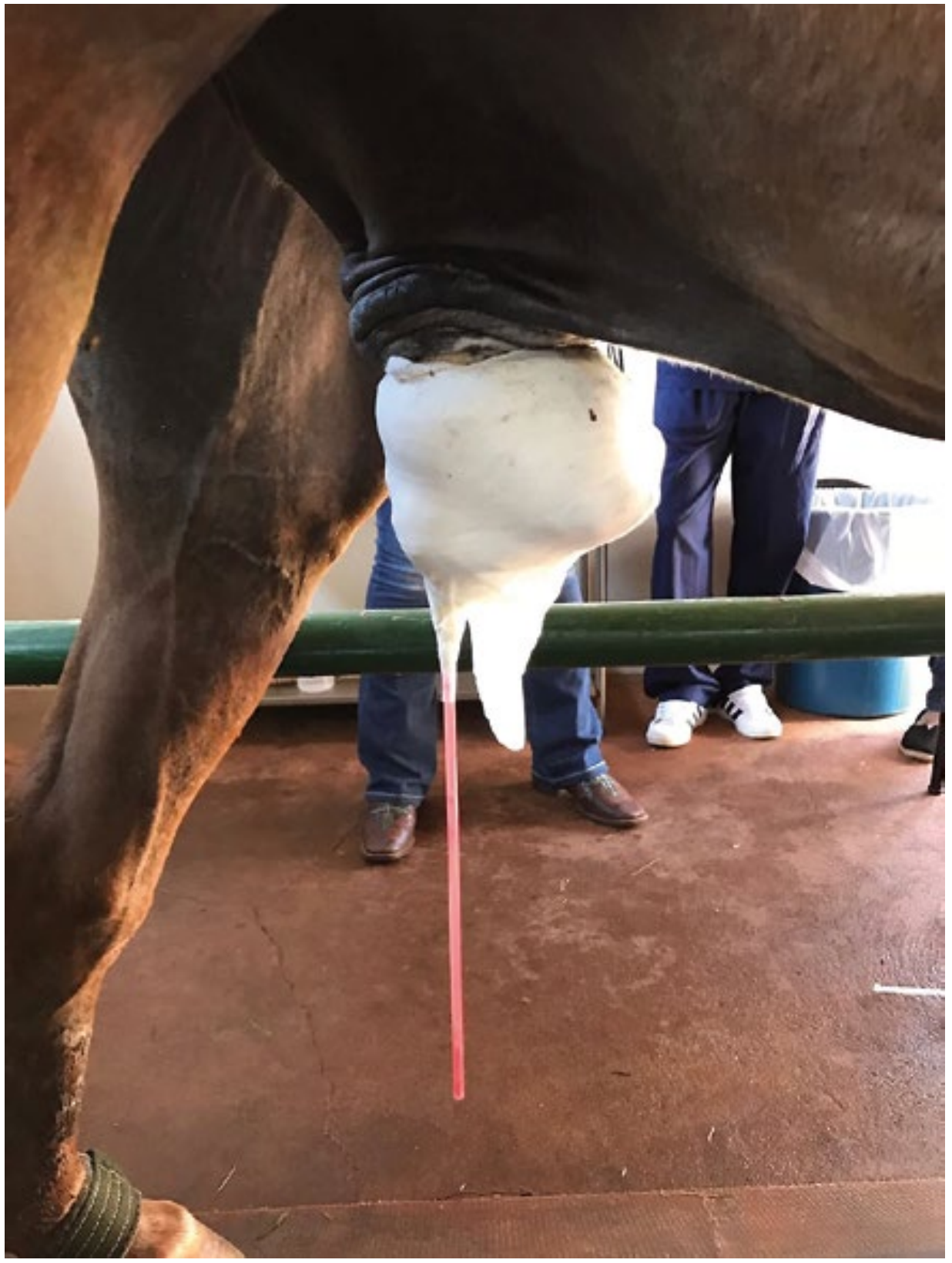

Figura 3 - Cateter utilizado como guia uretral para realização de penectomia parcial em equino. Fonte: Arquivo pessoal. 


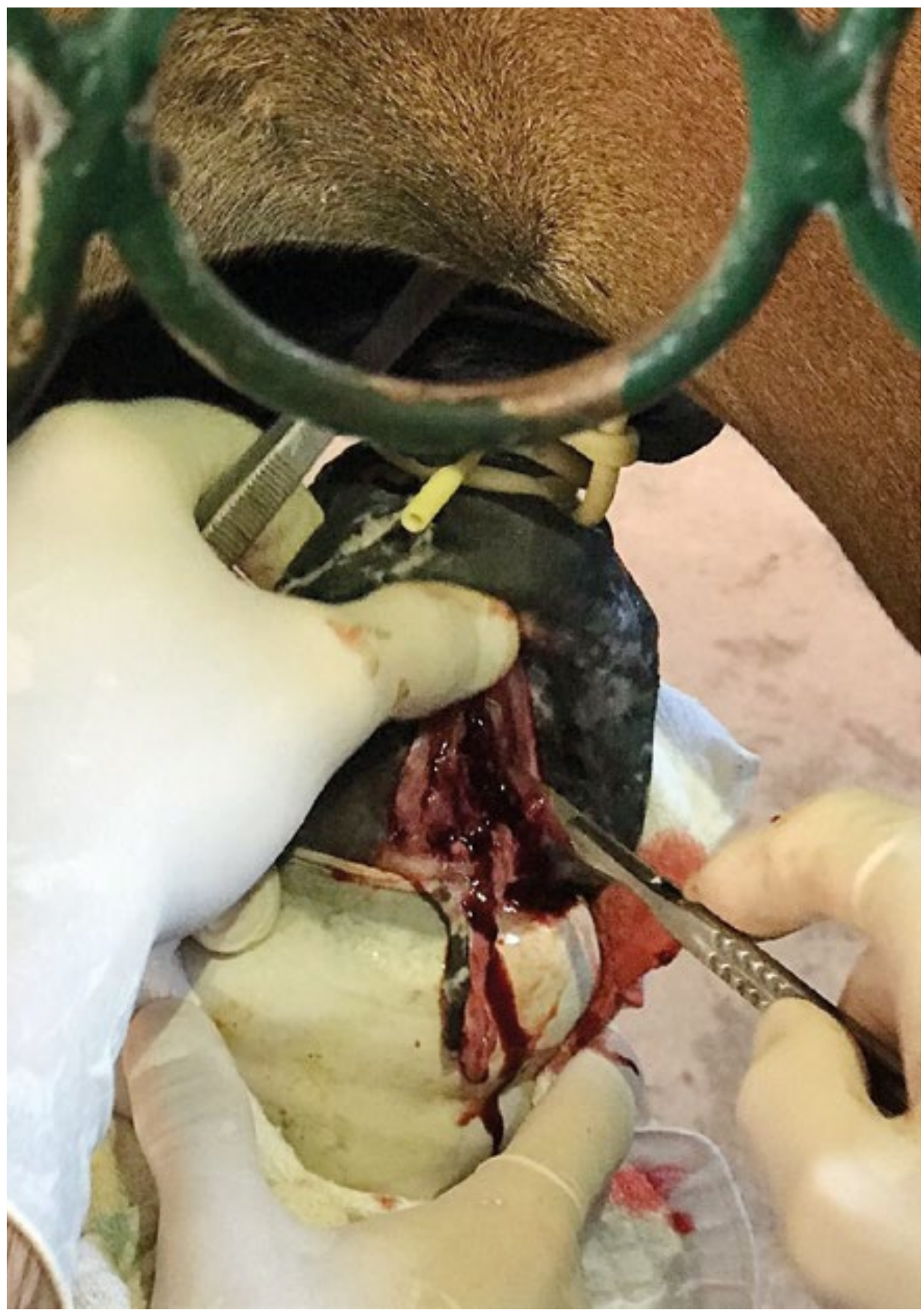

Figura 4 - Incisão em pênis equino feita em formato de triângulo invertido. Fonte: Arquivo pessoal.
O CCE é uma neoplasia maligna de células da derme. As células escamosas podem formar massas diferenciadas e cordões alongados que se expandem aleatoriamente por tecidos próximos (SCOPEL, 2007). Os primeiros sinais clínicos do CCE envolvem o espessamento da epiderme, seguido de esfoliação leve, afinamento e ulceração da área acometida (ROCHA et al., 2010). As lesões em estágios mais avançados podem ser erosivas, com aparecimento de nódulos superficiais revestidos por pele normal (XAVIER, 2010).
A apresentação dos tumores pode ser do tipo produtivo ou erosivo. Os produtivos têm aparência de couve-flor, com tamanho variado e com ulcerações em sua superfície, podendo sangrar facilmente. Os erosivos, com aparecimento mais frequente, possuem particularidades que começam com úlceras rasas e encobertas com crostas, que adentram de forma lenta e gradual (XAVIER, 2010). As complicações aparecem, frequentemente, com infecções bacterianas secundárias (GOLDSCHMIDT; HENDRICK, 2002) e miíases (XAVIER, 2010), resultando 
em exsudato purulento na superfície da massa tumoral (GOLDSCHMIDT; HENDRICK, 2002).

Neste caso, o diagnóstico foi confirmado pelo exame histopatológico, cuja microscopia revelou neoplasia maligna invadindo a derme profunda, caracterizada por ilhas de células epiteliais com núcleo amplo, pleomórfico e nucléolos múltiplos exuberantes, presença de raras figuras de mitoses e formação de pérolas córneas e estroma fibroso, achado microscópico encontrado também por Silva et al. (2015) - aqui, o exame histológico verificou ninhos de queratinócitos pleomórficos com queratinização individual das células.

O exame histopatológico, além de exames clínicos e complementares, é de extrema importância para a confirmação do diagnóstico de CCE genital em equinos (RABBERS et al., 2014).

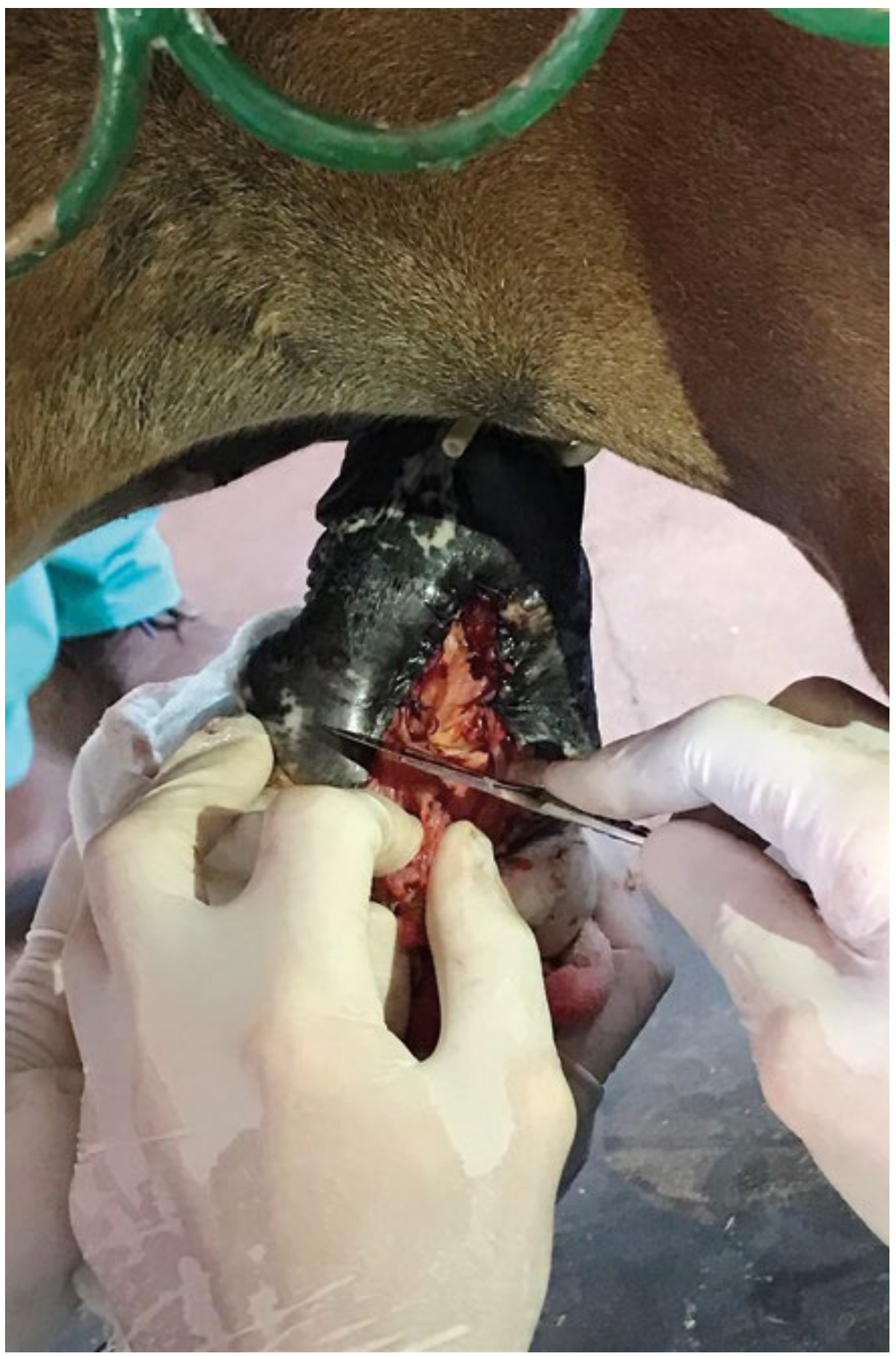

Figura 5 - Ressecção pela uretra peniana estendendo-se da base da incisão triangular, com ângulo moderadamente oblíquo na direção cranial do pênis. Fonte: Arquivo pessoal. 


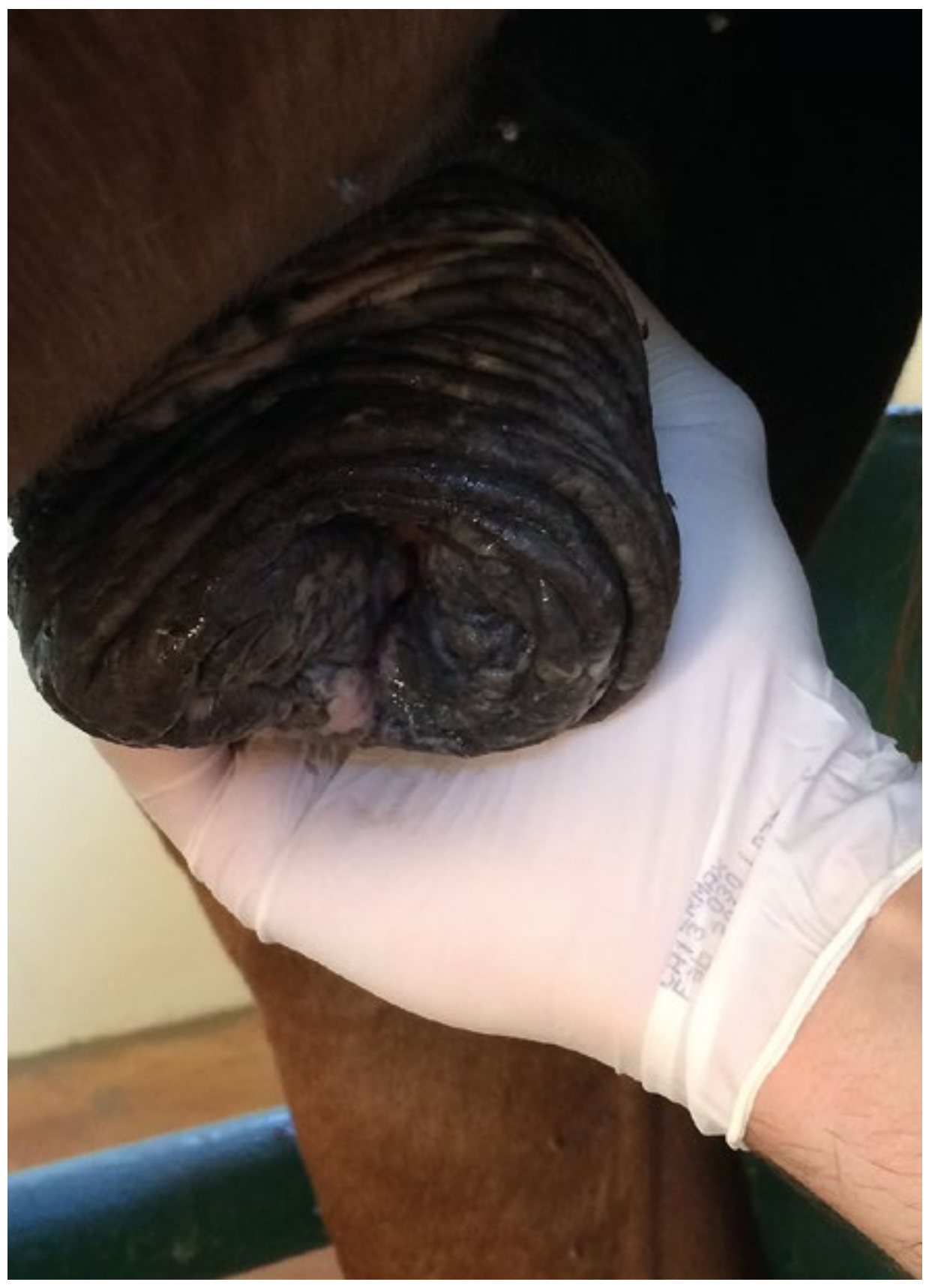

Figura 6 - Doze dias de pós-operatório após a retirada dos pontos.

Fonte: Arquivo pessoal.

\section{Conclusão}

A técnica cirúrgica de amputação da região acometida pela neoplasia apresentou-se eficaz para este caso, em que havia comprometimento de pênis. Houve rápida recuperação do animal, com melhora dos seus parâmetros fisiológicos e retorno gradual do processo de micção, sem complicações em decorrência do procedimento. (a)

\section{Referências}

BATAIER, M. N. et al. Carcinoma de células escamosas em prepúcio de equino: relato de caso. Revista Cientifica Eletrônica de Medicina Veterinária, Garça, ano 9, n. 18, 2012. Disponível em: <https://bit.ly/2PIttR8>. Acesso em: 18 de fev. 2018.

CARLOS, C. S. J. D. et al. Carcinoma de células escamosas em pênis eqüino: relato de caso. In: CONGRESSO DE INICIAÇÃO CIENTíFICA DA FEPI, 8., 2016, Itajubá. Anais... Itajubá: Centro Universitário de Itajubá, 2016. Disponível em: <https://bit.ly/2JQ9yu8>. Acesso em: 7 out. 2018.

GOLDSCHMIDT, M. H.; HENDRICK, M. J. Tumors of the skin and soft tissues. In: MEUTEN, D. J. Tumors in domestic animals. 4. ed. Ames: lowa State Press, 2002. p. 45-118. 
PEREIRA, E. C. et al. Carcinoma de células escamosas em um equino. Revista de Educação Continuada em Medicina Veterinária e Zootecnia do CRMV-SP, São Paulo, v. 10, n. 1, p. 67, 2012.

RABBERS, A. S. et al. Diagnóstico clinico, laboratorial e tratamento cirúrgico do carcinoma de células escamosas no genital de equinos machos: relatos de dois casos. Revista Brasileira de Ciência Veterinária, Niterói, v. 21, n. 1, p. 1218, 2014.

ROCHA, J. R. et al. Carcinoma de células escamosas em cães: relato de caso. Revista Científica Eletrônica de Medicina Veterinária, Garça, n. 14, 2010. Disponível em: <https://bit. ly/2Fclibz> Acesso em: 18 fev. 2018.

SCOPEL, D. et al. Estudo retrospectivo da casuística de carcinoma de células escamosas em felinos, bovinos, caninos, eqüinos e ovinos entre os anos de 2002 e 2006 no LRD/ UFPel. In: CONGRESSO DE INICIAÇÃO CIENTÍFICA, 16.; ENCONTRO DE PÓS-GRADUAÇÃO, 9., 2007. Anais... Pelotas: Universidade Federal de Pelotas, 2007.
SCOTT, D.W.; MILLER, W. H. J. Dermatologia equina. Buenos Aires: Intermédica, 2004.

SILVA, S. C. S. et al. Carcinoma de células escamosas em equino com metástase pulmonar: relato de caso. Revista Brasileira de Higiene e Sanidade Animal, Fortaleza, v. 9, n. 4, p. 689-698, 2015.

VAN DEN TOP, J. G. et al. Penile and preputial tumours in the horse: a retrospective study of 114 affected horses. Equine Veterinary Journal, Newmarket, v. 40, n. 6, p. 528-532, 2008.

XAVIER, F. S. Lesões proliferativas de pênis e prepúcio eqüinos. 2010. 47 f. Dissertação (Mestrado em Veterinária) Universidade Federal de Pelotas, Pelotas, 2010.

XAVIER, F. S.; NOGUEIRA, C. E. W.; FERNANDES, C. G. Estudo retrospectivo e preliminar de carcinomas de células escamosas em trato genital masculino em equinos, durante o período de 1983 a 2008. In: ENCONTRO DE PÓS-GRADUAÇÃO, 10., 2008, Pelotas. Anais... Pelotas: Universidade Federal de Pelotas, 2008. Disponível em: <https://bit.ly/2qxultB>. Acesso em: 18 fev. 2018. 